\title{
Evaluating Pollination Deficits in Pumpkin Production in New York
}

\author{
J. D. PETERSEN, ${ }^{1}$ A. S. HUSETH, and B. A. NAULT \\ Department of Entomology, Cornell University, New York State Agricultural Experiment Station, Geneva, NY 14456
}

Environ. Entomol. 43(5): 1247-1253 (2014); DOI: http://dx.doi.org/10.1603/EN14085

\begin{abstract}
Potential decreases in crop yield from reductions in bee-mediated pollination services threaten food production demands of a growing population. Many fruit and vegetable growers supplement their fields with bee colonies during crop bloom. The extent to which crop production requires supplementary pollination services beyond those provided by wild bees is not well documented. Pumpkin, Cucurbita pepo L., requires bee-mediated pollination for fruit development. Previous research identified the common eastern bumble bee, Bombus impatiens (Cresson), as the most efficient pumpkin pollinator. Two concomitant studies were conducted to examine pollination deficits in New York pumpkin fields from 2011 to 2013. In the first study, fruit weight, seed set, and B. impatiens visits to pumpkin flowers were compared across fields supplemented with $B$. impatiens colonies at a recommended stocking density of five colonies per hectare, a high density of 15 colonies per hectare, or not supplemented with bees. In the second study, fruit weight and seed set of pumpkins that received supplemental pollen through hand-pollination were compared with those that were openpollinated by wild bees. Results indicated that supplementing pumpkin fields with B. impatiens colonies, regardless of stocking density, did not increase fruit weight, seed set, or B. impatiens visits to pumpkin flowers. Fruit weight and seed set did not differ between hand- and open-pollinated treatments. In general, we conclude that pumpkin production in central New York is not limited by inadequate pollination services provided by wild bees and that on average, supplementation with $B$. impatiens colonies did not improve pumpkin yield.
\end{abstract}

KEY WORDS Bombus impatiens, Cucurbita pepo, fruit weight, pollen limitation, seed set

The global supply of European honey bees, Apis mellifera L., is growing slower than their demand for pollination services of many agricultural crops (Aizen and Harder 2009). Consequently, pollination services provided by alternative managed bees and wild bees continue to be evaluated (Stubbs and Drummond 2001, Lye et al. 2011, Garibaldi et al. 2013). Pumpkin, Cucurbita pepo L., is dependent on bee-mediated pollination to produce fruit (Skinner and Lovett 1992), and an increase in bee visits to female pumpkin flowers results in larger fruit (Artz and Nault 2011). Many growers supplement their pumpkin fields with A. mellifera colonies during bloom to provide insurance against low crop production due to possible pollination deficits (Delaplane and Mayer 2000). The recommendation to supplement pumpkin fields with $A$. mellifera colonies assumes that wild bees do not provide sufficient pollination to maximize fruit yield. The addition of A. mellifera colonies increased pumpkin fruit weight by $4-28 \%$ in Illinois (Walters and Taylor 2006), but a study in New York showed no significant increases in pumpkin yield when fields were supplemented with A. mellifera colonies (Petersen et al. 2013).

\footnotetext{
${ }^{1}$ Corresponding author, e-mail: jessdpetersen@gmail.com.
}

Pollination deficits can be assessed by comparing fruit yield and seed set in fields supplemented with bee colonies during bloom with those not supplemented. Deficits also can be evaluated by comparing fruit yield from flowers that are hand-pollinated with those that are open-pollinated (i.e., pollen limitation; Thomson 2001). When conducted simultaneously, these two complementary methods for determining pollination deficits in crop production provide an estimation of the pollination needs for a pollinator-dependent crop such as pumpkin.

Bombus impatiens (Cresson), the common eastern bumble bee, is a wild bee that commonly visits pumpkin flowers in New York, and is also available commercially. B. impatiens is the most efficient pollinator of pumpkin on an individual flower-visit basis (Artz and Nault 2011). Compared with the two other abundant bee species in this cropping system (A. mellifera and Peponapis pruinosa (Say)), B. impatiens deposits more pollen on the stigma per visit, contacts the stigma more frequently, and requires fewer visits to female flowers to produce large fruit (Artz and Nault 2011). This efficiency study suggests that supplementing pumpkin fields with $B$. impatiens colonies might lead to greater fruit yield compared with fields supplemented with A. mellifera colonies. However, supplementing pumpkin fields with $B$. impatiens colonies did 
not increase fruit yields at the stocking density recommended by the supplier, Koppert Biological Systems, Inc., of five colonies per hectare (Petersen et al. 2013). Other studies have shown that supplementing lowbush blueberries, Vaccinium angustifolium Aiton, with B. impatiens colonies improved fruit yield at higher stocking densities (7.5-10 colonies per hectare; Stubbs and Drummond 2001, Drummond 2012). If pollination deficits are limiting production, pumpkin fruit yield could be increased with a higher stocking density of B. impatiens colonies.

Pollen limitation, which is the extent to which pollen deposition by bees is insufficient to maximize fruit yield, has not been experimentally evaluated across all cultivated crops that require bee-mediated pollen transfer (Thomson 2001). There is evidence for insufficient bee-mediated pollination in crops such as sweet cherry, Prunus avium (L.) (Holzschuh et al. 2012), apple, Malus domestica Borkh. (Garratt et al. 2013), canola, Brassica napus L. and Brassica rapa L. (Morandin and Winston 2005), coffee, Coffea arabica L. (Ricketts et al. 2004), and cantaloupe, Cucumis melo L. (Strauss and Murch 2004), but it is not known whether bee-mediated pollination limits pumpkin production in central New York.

This study assessed whether pollination deficits existed in pumpkin cropping systems using two complementary approaches. The first objective was to determine whether increasing the stocking density of $B$. impatiens colonies in pumpkin fields would increase fruit yield. We hypothesized that fruit yield in fields supplemented with a high density of B. impatiens colonies ( 15 colonies per hectare) would be greater than yield in fields supplemented with the recommended stocking density of $B$. impatiens colonies ( 5 colonies per hectare). The second objective was to determine if pumpkin is a pollen-limited crop by comparing fruit weight of pumpkins that were either pollinated naturally by wild bees or pollinated with supplemental pollen by hand. We hypothesized that pumpkin was pollen-limited and that fruit produced from flowers that were pollinated by hand would be larger than those pollinated by natural populations of wild bees (i.e., open-pollinated).

\section{Materials and Methods}

B. impatiens Stocking Density Experiment. This experiment was conducted in commercial pumpkin fields in 2012 and 2013 in central New York, USA. Fields ranged in size from 0.5 to 10 hectares. Fields of similar size were grouped and randomly assigned one of the three supplementation treatments: B. impatiens colonies at the standard stocking density ( 5 colonies per hectare; $n=10$ fields), B. impatiens colonies at a high stocking density ( 15 colonies per hectare; $n=10$ fields), or not supplemented with bees $(n=10$ fields).

The jack-o-lantern variety, Cucurbita pepo L. variety 'Gladiator', was transplanted in small plots in all fields. Gladiator was chosen because it generally produces one large fruit per plant rather than many fruit, which would compete for plant resources during de- velopment. Transplants were obtained by planting seeds in seedling trays $(4 \times 8$ cells $)$ containing Cornell soil mix (Boodley and Sheldrake 1977) and maintained under greenhouse conditions. Multiple plantings were made spanning a 3 -wk period to create an ample source of 1-2 leaf stage plants. In each pumpkin field, plants that matched the size of field-sown plants were transplanted into three plots of 10 plants each (two adjacent rows of five plants; $n=30$ transplants per field). Plant spacing in small plots matched plant spacing in the field (e.g., between-row spacing $=2 \mathrm{~m}$, within-row spacing $=1 \mathrm{~m}$ ). All plots were located at least $20 \mathrm{~m}$ from field edges and were arranged to capture the variability of the field topography and edge habitats. Fruit produced from the transplants in the small plots were harvested and weighed at the end of the growing season. Fruit yield was calculated by averaging all marketable fruit weights within plots and then averaging fruit weights across all three small plots in each field. Additionally, viable seeds were counted from a subset of the fruit ( $n=6$ fruit per field), and counts were averaged for each field. Seeds were considered viable if they appeared fully formed.

In mid-July, when pumpkin plants were beginning to bloom, B. impatiens colonies were stocked in the fields. Commercially reared B. impatiens colonies were acquired from Koppert Biological Systems, Inc. (Howell, MI). B. impatiens colonies, also known as QUADs (one QUAD contains four colonies), were placed within the field equidistant from each other. No other managed B. impatiens colonies were within $1 \mathrm{~km}$ of experimental fields; $1 \mathrm{~km}$ is the most common foraging distance observed for Bombus spp. (Osborne et al. 1999, Hagen et al. 2011).

Bee visits to pumpkin flowers were assessed visually in three transects in each field. Transects consisted of two rows of pumpkins, including the area of our small plots, and extended $40 \mathrm{~m}$ beyond the plots for a total of $44 \mathrm{~m}$. The number of each bee species visiting all pumpkin flowers in each transect was counted once a week for three consecutive weeks (=rounds), which spanned the majority of the blooming period. Sampling was conducted when flowers were open, between 0600-1100 hours, on sunny to partly cloudy days with minimal wind $(<15 \mathrm{~km} / \mathrm{h})$. Transects were surveyed for a total of $10 \mathrm{~min}$ each by slowly walking between the rows and then recording the numbers of each bee species visiting every flower and the total number of flowers within each transect. A flower "visit" was recorded if the bee came in contact with the reproductive parts of the pumpkin plant. Average bee visitation per flower per field was calculated for each species as follows. For each bee species and each sampling round, both the number of flower visits by bees and the total number of flowers across all three transects were summed. Total number of bee visits to flowers was divided by the total number of flowers to achieve a flower visitation frequency metric for each round. Flower visitation frequencies were then averaged across the three sampling rounds for each field. A subsample of bees was collected each year and identified in the lab, and voucher specimens were 
Table 1. Summary statistics including field size (ha), year data were collected, average fruit weight ( $\pm \mathrm{SEM} ; \mathrm{kg}$ ), and sample sizes of open-pollinated (OP) and hand-pollinated (HP) treatments

\begin{tabular}{lcrrrr}
\hline \hline \multicolumn{1}{c}{ Field } & Field size (ha) & Year & $\begin{array}{c}\text { Avg fruit wt } \\
\text { (SEM; kg) }\end{array}$ & $\begin{array}{r}\text { OP } \\
(n)\end{array}$ & $\begin{array}{r}\text { HP } \\
(n)\end{array}$ \\
\hline Research N & 0.6 & 2011 & $9.12(0.29)$ & 22 & 21 \\
Shamrock & 5.7 & 2012 & $4.84(0.39)$ & 23 & 26 \\
HWY251 & 3.7 & 2012 & $10.34(0.58)$ & 11 & 13 \\
Research S & 0.6 & 2012 & $9.53(0.24)$ & 28 & 26 \\
Mott & 3.8 & 2013 & $3.59(0.36)$ & 7 & 6 \\
Tomion & 4.0 & 2013 & $4.22(0.36)$ & 10 & 10 \\
Crittenden & 0.6 & 2013 & $4.06(0.16)$ & 17 & 13 \\
Bear & 3.6 & 2013 & $1.42(0.09)$ & 12 & 12 \\
BC East & 4.9 & 2013 & $5.32(0.27)$ & 9 & 9 \\
\hline
\end{tabular}

deposited at the Insect Collections at Cornell University (CUIC), Ithaca, NY.

One-way analysis of variance (ANOVA) procedure was used to identify differences in fruit yield and bee visitation metrics among supplementation treatments. "Average fruit weight," "average viable seed set," "average bee visitation frequency per flower" (all three species combined), and "B. impatiens visitation frequency per flower" were dependent variables, with supplementation treatment as the independent variable. A multiple linear regression was conducted if the dependent variable differed significantly between years $(P<0.05)$, including "year" as a factor in the model. All analyses were conducted using the function $l m$ in R v. 3.0.2 (R Core Team 2013).

Pollen Limitation Experiment. This experiment was conducted in nine commercial pumpkin fields (Table 1) that were not supplemented with either $A$. mellifera or B. impatiens colonies. In each field, flowers were randomly selected to be either hand-pollinated or open-pollinated. For the hand-pollinated treatment, female flowers from different plants (10-30 plants per field) were pollinated by brushing a homogenous sample of pollen collected from five male flowers onto the stigma of a single female flower using a paintbrush to simulate maximum pollen deposition. Flowers in the hand-pollinated treatment were permitted visits by bees before and following the supplemental pollen procedure. Open-pollinated flowers also were randomly selected from each field (10-30 plants per field). To eliminate resource competition that occurs between multiple fruit on the same plant, all experimental plants were monitored weekly, and all immature female flowers were removed to ensure that only the "treatment flower" and resulting fruit was produced. Fields were visited between two and five times to initiate treatments. During each visit, equal numbers of hand- and open-pollinated flowers were identified, treated as either hand- or open-pollinated, and marked for harvest. Final numbers of fruit in both hand- and open-pollinated treatments varied between fields because some treatment flowers aborted. All mature fruit that developed from hand- and openpollination treatments were harvested and weighted. In each field and in each treatment, numbers of viable seeds were counted from a subsample of the total fruit collected.
Actual fruit weights could not be compared between treatments because pumpkin cultivars differed across fields. Thus, fruit weights were standardized in each field using z-scores $(z=(x-\mu) / \sigma)$, where $x$ represents the individual fruit weight, $\mu$ is the mean weight for each field, and $\sigma$ is the standard deviation of fruit weights for each field. Standardization was performed separately for each field. The number of viable seeds per fruit was standardized in the same manner. A multiple linear regression was conducted using the function $l m$ in $\mathrm{R}$ with "pollination treatment" (i.e., whether or not the fruit was hand-pollinated or open-pollinated) predicting "standardized fruit weight" and "standardized viable seed set" (R Core Team 2013). "Field" was included as a factor in the model to avoid pseudoreplication ( $n=9$ fields) and to use the appropriate degrees of freedom for the model.

\section{Results}

B. impatiens Stocking Density Experiment. Plants produced $1.1(\mathrm{SD}=0.18)$ fruit per plant on average. "Average fruit weight" across all treatments did not differ between "years" $(t=0.89 ; \mathrm{df}=1,28 ; P=0.388)$, so these data were pooled across years. "Average viable seed set" did not differ between "years" $(t=0.86$; $\mathrm{df}=1,28 ; P=0.858)$, so these data also were pooled across years. "Average fruit weight" in pumpkin fields supplemented with B. impatiens, regardless of stocking density, did not differ from those that were not supplemented $(F=0.25 ; \mathrm{df}=2,27 ; P=0.777 ;$ Fig. $1 \mathrm{~A})$. There were also no significant differences in "viable seed set" between supplementation treatments $(F=$ $0.66 ; \mathrm{df}=2,27 ; P=0.522 ;$ Fig. $1 \mathrm{~B}$ ) .

Approximately $99 \%$ of pumpkin flower visits were by three species, $P$. pruinosa, A. mellifera, and B. impatiens. In $2012, P$. pruinosa was the most abundant species $(n=1453)$, followed by A. mellifera $(n=867)$ and B. impatiens $(n=841)$ for a total of 3211 individuals across all fields. In 2013, B. impatiens was the most abundant $(n=1466)$, followed by A. mellifera $(n=$ 734) and P. pruinosa $(n=408)$ for a total of 2617 individuals across all fields. "Bee visitation frequency per flower" did not significantly differ between supplementation treatments $(F=2.45 ; \mathrm{df}=2,27 ; P=$ $0.105)$, and pumpkin flower visitation for each of the three main pollinator species, in each treatment are presented in Fig. 1C.

In 2013 , there were significantly more "B. impatiens visits per flower" compared with $2012(t=4.46$; $\mathrm{df}=$ $1,28 ; P<0.0001)$. Therefore, "year" was included as a categorical factor in a multiple linear regression model along with "supplementation treatment" as a factor predicting "B. impatiens visits per flower." The full model was significant $(F=7.40$; $\mathrm{df}=3,26 ; P=$ 0.001 ), but the average " $B$. impatiens visits per flower" did not differ between supplementation treatments $(P=0.35$; Fig. 1D).

Pollen Limitation Experiment. In total, 136 handpollinated and 139 open-pollinated fruit were evaluated across all years and fields. The model predicting 
(A)
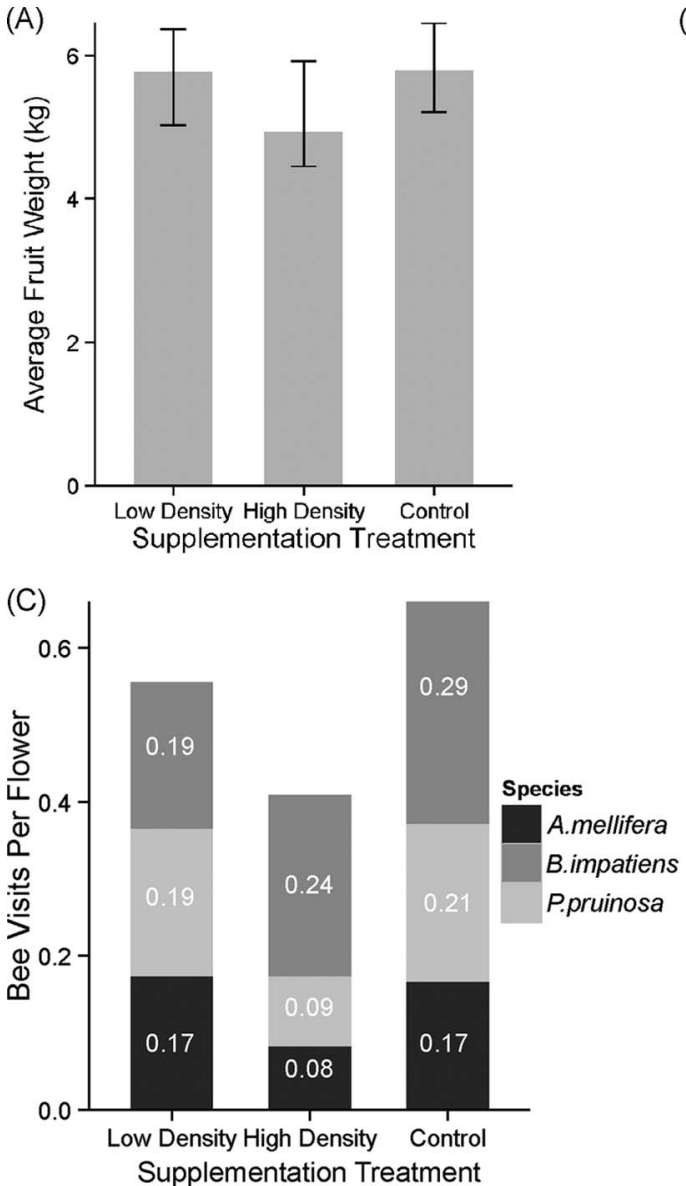

(B)

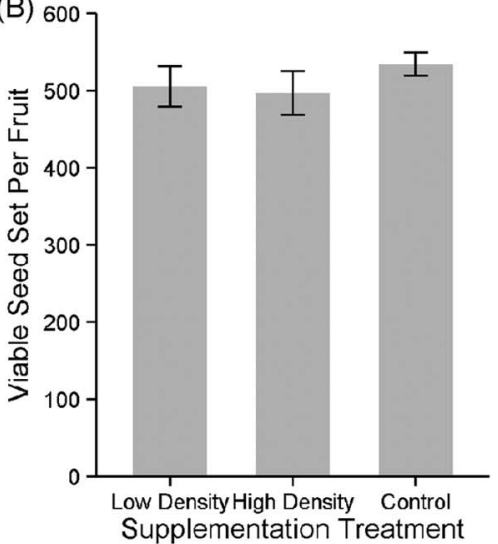

(D)

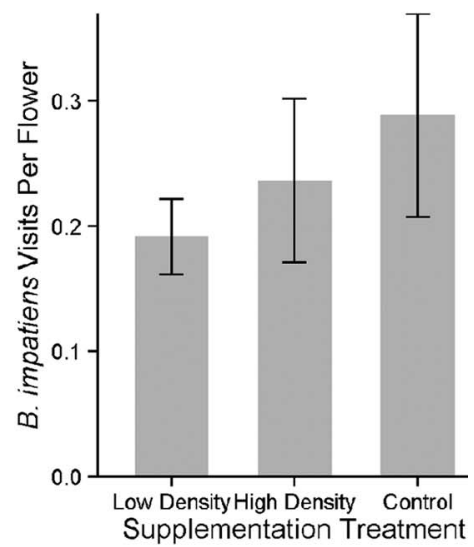

Fig. 1. Average responses $( \pm$ SEM) of pollinator treatments: low density $B$. impatiens supplementation ( 5 colonies per hectare, $n=10)$, high density B. impatiens supplementation ( 15 colonies per hectare, $n=10)$, and no supplementation $(n=$ 10) for (A) fruit weight (kg), (B) seed set (number of viable seeds), (C) bee visits per pumpkin flower for each of the three most common bee species: A. mellifera, P. pruinosa, and B. impatiens, and (D) B. impatiens visits per pumpkin flower.

"standardized fruit weight" was not significant $(F=$ 1.40; $\mathrm{df}=9,265 ; P=0.999)$. "Standardized fruit weight" did not differ between hand- $(0.063 \pm 0.093$, mean \pm SEM) and open-pollinated treatments $(-0.062 \pm 0.078 ; P=0.307$; Fig. 2 A $)$.

The number of viable seeds was determined from 55 hand-pollinated fruit and 52 open-pollinated fruit across all fields. The model predicting "standardized viable seed set" was not significant $(F=0.08$; $\mathrm{df}=8$, $98 ; P=0.999)$. "Standardized viable seed set" did not differ between hand- $(0.090 \pm 0.171$, mean \pm SEM $)$ and open-pollinated treatments $(-0.095 \pm 0.143 ; P=$ 0.424; Fig. 2B). The quantity of pollen delivered by wild bees to the stigma was not a limiting factor in the production of marketable fruit in pumpkin cropping systems in our study.

\section{Discussion}

Fruit yield was not affected by supplementing commercial pumpkin fields with B. impatiens colonies. Yield did not differ among fields supplemented with a standard stocking density of five colonies per hectare, 15 colonies per hectare, or those not supplemented. Flower visits by $B$. impatiens did not differ between fields supplemented with $B$. impatiens colonies, regardless of stocking density, and fields not supplemented with bumble bees. Thus, the expectation that supplementing pumpkin fields with $B$. impatiens colonies to improve pollination and thereby increase fruit yield was not evident in this study. Furthermore, the addition of B. impatiens colonies at either stocking density did not influence the flower visitation frequency of the total bee community. Fruit weight and seed set from pumpkins that were hand-pollinated did not differ from those that were open-pollinated, indicating that pumpkin was not pollen-limited in this study. Our results from these concomitant studies indicate that on average, wild bees, including feral colonies of A. mellifera, provide sufficient pollination services required to maximize the production of jacko-lantern pumpkins in central New York.

Few studies have investigated the effects of supplementing pollinator-dependent crops with B. impa- 


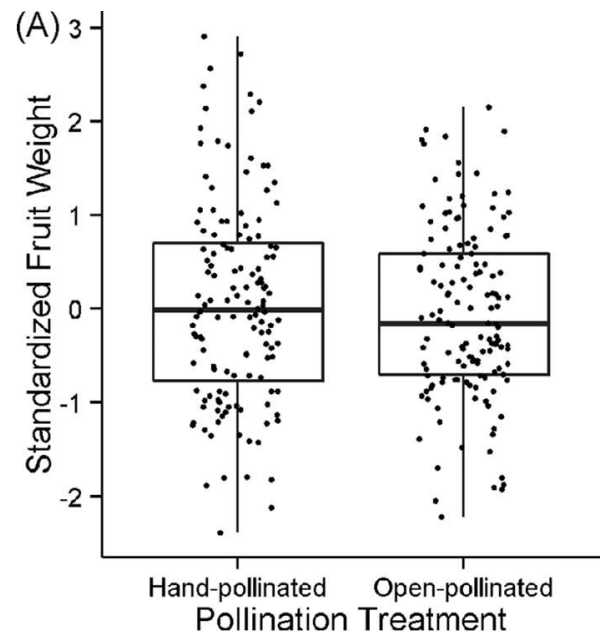

(B)

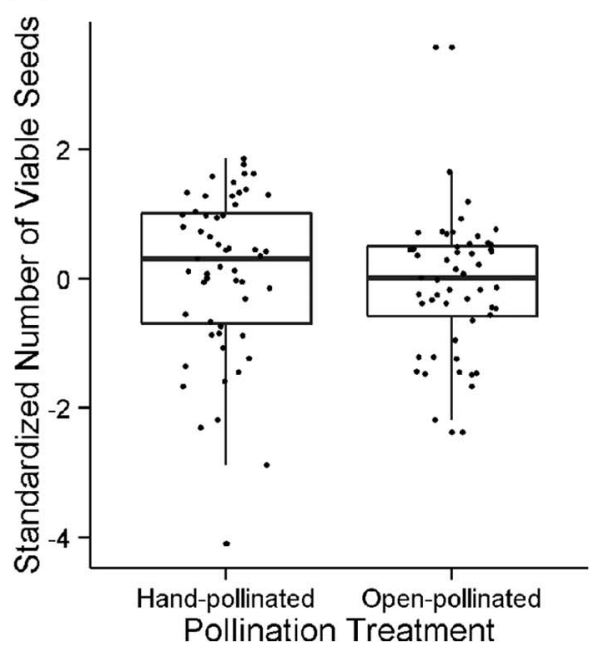

Fig. 2. Average standardized (A) fruit weight and (B) number of viable seeds ( \pm SEM) in hand and open-pollinated fruit.

tiens colonies on fruit yield. Two studies in perennial fruit crops, raspberry, Rubus idaeus (Lye et al. 2011), and lowbush blueberry (Stubbs and Drummond 2001), indicated that fields supplemented with Bombus spp. increased fruit yield. Research has indicated that B. impatiens is an efficient pollinator of pumpkin (Artz and Nault 2011, Artz et al. 2011) and other cucurbits (Stanghellini et al. 1998a,b), but supplementing pumpkin fields with $B$. impatiens colonies at the recommended rate of five colonies per hectare did not increase fruit yield (Petersen et al. 2013). In our study, a high density of $B$. impatiens colonies ( 15 colonies per hectare) failed to produce greater fruit yields compared with fields not supplemented with bees. These results indicate that supplementation with this alternative managed pollinator is neither economically viable for growers (at $\approx$ US $\$ 200$ per four colonies) nor needed to improve pumpkin yield in central New York.
Butternut squash, Cucurbita moschata Duchesne, grown in Massachusetts, which has a similar landscape and temperate climate as New York, was determined to not be pollen-limited (Hladun and Adler 2009, Cavanagh et al. 2010). In contrast, cantaloupe grown in California was determined to be a pollen-limited crop (Strauss and Murch 2004). Coffee was considered as pollen-limited only for trees that were far from forest patches, whereas those near and intermediate to the forest were not considered pollen-limited (Ricketts et al. 2004). The landscape surrounding pumpkin fields in the northeastern United States may offer more habitat and floral resources to sustain wild bee populations compared with landscapes in California, or the corn- and soybean-dominated Midwest (Walters and Taylor 2006), which can potentially explain why cucurbit crops may not be pollen-limited in the northeastern United States (Winfree et al. 2008).

Documentation of pollen limitation in other agricultural crops may be inflated due to biases for only publishing significant results (Knight et al. 2006). The response variable (e.g., fruit weight, seed set, fruit set) may also confound differences in prevalence of pollen limitation in other cultivated crops (Knight et al. 2006). Moreover, artificial supplementation of crops with large amounts of pollen may not simulate maximum yield for several reasons including damage to the stigma during application, pollen tube crowding, missed timing of stigma receptivity to pollen, and pollen removal following application (Young and Young 1992). The hand-pollination procedure used in our study may or may not have had similar technical problems as those described above. However, results obtained from our pollen limitation experiment corroborated the results from our B. impatiens supplementation experiment, indicating that pumpkin is not a pollen-limited crop in our region. These results indicate that wild bees supply sufficient pollination for maximum pumpkin yield in central New York. Recent research at a landscape-scale in the same region indicated that perhaps certain conditions of the landscape surrounding pumpkin fields may support fewer wild bees, and thus perhaps benefit from supplementation (Petersen and Nault 2014). Similarly, research in the mid-Atlantic indicates that local farming practices such as tillage and irrigation as well as soil content influence wild bee abundance in pumpkin fields (Shuler et al. 2005, Julier and Roulston 2009). Localand landscape-scale factors may be important to consider when deciding what pumpkin fields may benefit from supplemental pollination.

Wild bees contribute to crop yield in multiple production systems globally (Garibaldi et al. 2013) and in specific crops including sunflower, Helianthus annuus L. (Greenleaf and Kremen 2006a), coffee (Veddeler et al. 2008), sweet cherry (Holzschuh et al. 2012), highbush blueberry, Vaccinium corymbosum L. (Isaacs and Kirk 2010), tomato, Solanum lycopersicum L. (Greenleaf and Kremen 2006b), and squash, C. moschata (Hoehn et al. 2008). Wild bees such as P. pruinosa and B. impatiens and feral colonies of A. mellifera are providing maximum pollination services to pump- 
kin in central New York. These conclusions are consistent with other studies that suggest wild bees sufficiently pollinate pumpkins in the mid-Atlantic (Julier and Roulston 2009). Other major pumpkingrowing regions such as Illinois and California, where the landscape and available flowering resources for wild pollinators may differ from that of central New York, would benefit from pollen-limitation experiments to determine if supplementation of fields with managed bees during bloom is necessary for maximizing production.

\section{Acknowledgments}

We thank Koppert Biological Systems for donating a portion of the bumble bee QUADs. We also are grateful to the growers who allowed us to conduct this research on their farms and to the summer workers who helped assist in data collection. This research was supported by New York State Agriculture and Markets Specialty Crops Block Grant 20122013 contract number 67811.

\section{References Cited}

Aizen, M. A., and L. D. Harder. 2009. The global stock of domesticated honey bees is growing slower than agricultural demand for pollination. Curr. Biol. 19: 915-918.

Artz, D. R., C. L. Hsu, and B. A. Nault. 2011. Influence of honey bee, Apis mellifera, colonies and field size on foraging activity of native bee species in pumpkin fields. Environ. Entomol. 40: 1144-1158.

Artz, D. R., and B. A. Nault. 2011. Performance of Apis mellifera, Bombus impatiens, and Peponapis pruinosa $\mathrm{Hy-}$ menoptera: Apidae) as pollinators of pumpkin. J. Econ. Entomol. 104: 1153-1161.

Boodley, J. W., and R. Sheldrake. 1977. Cornell peat-lite mixes for commercial plant growing. Cornell Inf. Bull. 43.

Cavanagh, A. F., L. S. Adler, and R. V. Hazzard. 2010. Buttercup squash provides a marketable alternative to blue hubbard as a trap crop for control of striped cucumber beetles (Coleoptera: Chrysomelidae). Environ. Entomol. 39: 1953-1960.

Delaplane, K. S., and D. F. Mayer. 2000. Crop pollination by bees. CABI Publishing, New York, NY.

Drummond, F. 2012. Commercial bumble bee pollination of lowbush blueberry. Int. J. Fruit Sci. 12: 54-64.

Garibaldi, L. A., I. Steffan-Dewenter, R. Winfree, M. A. Aizen, R. Bommarco, S. A. Cunningham, C. Kremen, L. G. Carvalheiro, L. D. Harder, O. Afik, etal. 2013. Wild pollinators enhance fruit set of crops regardless of honey bee abundance. Science 339: 1608-1611.

Garratt, M.P.D., C. Truslove, D. Coston, R. Evans, E. Moss, C. Dodson, N. Jenner, J. Biesmeijer, and S. Potts. 2013. Pollination deficits in UK apple orchards. J. Pollination Ecol. 12: 9-14.

Greenleaf, S. S., and C. Kremen. 2006a. Wild bees enhance honey bees' pollination of hybrid sunflower. Proc. Natl. Acad. Sci. USA 103: 13890-13895.

Greenleaf, S. S., and C. Kremen. 2006b. Wild bee species increase tomato production and respond differently to surrounding land use in Northern California. Biol. Conserv. 133: 81-87.

Hagen, M., M. Wikelski, and W. D. Kissling. 2011. Space use of bumblebees (Bombus spp.) revealed by radio-tracking. PLoS ONE 6: el9997.
Hladun, K. R., and L. S. Adler. 2009. Influence of leaf herbivory, root herbivory, and pollination on plant performance in Cucurbita moschata. Ecol. Entomol. 34: 144-152.

Hoehn, P., T. Tscharntke, J. M. Tylianakis, and I. SteffanDewenter. 2008. Functional group diversity of bee pollinators increases crop yield. Proc. Biol. Sci. 275: 22832291.

Holzschuh, A., J. Dudenhöffer, and T. Tscharntke. 2012. Landscapes with wild bee habitats enhance pollination, fruit set and yield of sweet cherry. Biol. Conserv. 153: $101-107$.

Isaacs, R., and A. K. Kirk. 2010. Pollination services provided to small and large highbush blueberry fields by wild and managed bees. J. Appl. Ecol. 47: 841-849.

Julier, H. E., and T. H. Roulston. 2009. Wild bee abundance and pollination service in cultivated pumpkins: farm management, nesting behavior and landscape effects. J. Econ. Entomol. 102: 563-573.

Knight, T. M., J. A. Steets, and T. L. Ashman. 2006. A quantitative synthesis of pollen supplementation experiments highlights the contribution of resource reallocation to estimates of pollen limitation. Am. J. Bot. 93: 271-277.

Lye, G., S. N. Jennings, J. L. Osborne, and D. Goulson. 2011. Impacts of the use of nonnative commercial bumble bees for pollinator supplementation in raspberry. J. Econ. Entomol. 104: 107-114.

Morandin, L. A., and M. L. Winston. 2005. Wild bee abundance and seed production in conventional, organic, and genetically modified canola. Ecol. Appl. 15: 871-881.

Osborne, J., S. Clark, R. Morris, I. Williams, J. Riley, A. Smith, D. Reynolds, and A. Edwards. 1999. A landscape-scale study of bumble bee foraging range and constancy, using harmonic radar. J. Appl. Ecol. 36: 519-533.

Petersen, J. D., and B. A. Nault. 2014. Landscape diversity moderates the effects of bee visitation frequency to flowers on crop production. J. Appl. Ecol. (in press).

Petersen, J. D., S. Reiners, and B. A. Nault. 2013. Pollination services provided by bees in pumpkin fields supplemented with either Apis mellifera or Bombus impatiens or not supplemented. PLoS ONE 8: e69819.

R Core Team. 2013. R: a language and environment for statistical computing. R Foundation for Statistical Computing, Vienna, Austria. (http://www.R-project.org/).

Ricketts, T. H., G. C. Daily, P. R. Ehrlich, and C. D. Michener. 2004. Economic value of tropical forest to coffee production. Proc. Natl. Acad. Sci. USA 101: 12579-12582.

Shuler, R. E., T. H. Roulston, and G. E. Farris. 2005. Farming practices influence wild pollinator populations on squash and pumpkin. J. Econ. Entomol. 98: 790-795.

Skinner, J., and G. Lovett. 1992. Is one visit enough? Squash pollination in Tennessee. Am. Bee J. 132: 359-377.

Stanghellini, M., J. Ambrose, and J. Schultheis. 1998a. Seed production in watermelon: a comparison between two commercially available pollinators. HortScience 33: 28 30.

Stanghellini, M., J. Ambrose, and J. Schultheis. 1998b. Using commercial bumble bee colonies as backup pollinators for honey bees to produce cucumbers and watermelons. Horttechnology 8: 590-594.

Strauss, S. Y., and P. Murch. 2004. Towards an understanding of the mechanisms of tolerance: compensating for herbivore damage by enhancing a mutualism. Ecol. Entomol. 29: 234-239.

Stubbs, C. S., and F. A. Drummond. 2001. Bombus impatiens (Hymenoptera: Apidae): an alternative to Apis mellifera (Hymenoptera: Apidae) for lowbush blueberry pollination. J. Econ. Entomol. 94: 609-616. 
Thomson, J. D. 2001. Using pollination deficits to infer pollinator declines: can theory guide us? Conserv. Ecol. 5: 6 .

Veddeler, D., R. Olschewski, T. Tscharntke, and A. Klein. 2008. The contribution of non-managed social bees to coffee production: new economic insights based on farmscale yield data. Agrofor. Syst. 73: 109-114.

Walters, S. A., and B. H. Taylor. 2006. Effects of honey bee pollination on pumpkin fruit and seed yield. HortScience 41: $370-373$.
Winfree, R., N. M. Williams, H. Gaines, J. S. Ascher, and C. Kremen. 2008. Wild bee pollinators provide the majority of crop visitation across land-use gradients in New Jersey and Pennsylvania, USA. J. Appl. Ecol. 45: 793-802. Young, H. J., and T. P. Young. 1992. Alternative outcomes of natural and experimental high pollen loads. Ecology 73: $639-647$.

Received 31 March 2014; accepted 10 July 2014. 